\title{
EPISTEMOLOGIA: QUEM PRECISA DELA?
}

\author{
Susan Haack \\ University of Miami
}

\author{
Tradução: Tiago Luís Teixeira de Oliveira ${ }^{2}$ \\ Colégio Pedro II (CP II) \\ (iD) http://orcid.org/0000-0001-7793-9890 \\ E-mail: tiagoluis@ymail.com
}

\begin{abstract}
...como todos sabemos, existem conhecidos sabidos; existem coisas que sabemos que sabemos. Também sabemos que existem desconhecidos sabidos; ou seja, sabemos que existem coisas que não sabemos. Mas também existem desconhecidos não sabidos - aqueles que não sabemos que não sabemos. - Donald Rumsfeld. ${ }^{3}$
\end{abstract}

Em 2002, as ruminações de Donald Rumsfeld sobre as falhas da Inteligência militar dos EUA no Iraque ganharam o prêmio anual da Campanha do Inglês Simples (Plain English Campaign) pelo "comentário mais desconcertante feito por uma figura pública" - superando por pouco o de Arnold Schwarzenegger de que "o casamento gay é uma algo que deveria ser entre um homem e uma mulher", e o de que "tendo cometido suicídio político, o Partido Conservador está agora vivendo para se arrepender disso", de Christopher Patten. Eu também ri do contorcionismo verbal do secretário Rumsfeld; mas penso que ele tinha um ponto - um ponto epistemológico.

Que ponto era este ficará claro a seguir; mas primeiro preciso dizer algo sobre o que é epistemologia e como ela recai nos problemas do mundo real. Tendo trabalhado neste campo por décadas, eu me vejo invocando ideias epistemológicas todos os dias: quando considero, por exemplo, quais consequências tirar de um artigo que alega haver evidência empírica mostrando que adolescentes e jovens adultos deveriam ter preferência sobre crianças e pessoas mais velhas na alocação dos recursos médicos escassos; se "medicina baseada em evidência" é tão desejável

\footnotetext{
1 (C) 2011, 2015, 2018 Susan Haack. Toda solicitação para reimpressão, tradução, abreviar ou adaptar o artigo devem ser endereçadas à autora, shaack@law.miami.edu. Este artigo foi publicado primeiro em dinamarquês, sob o título de "Erkendelsesteori- hvem har brug for det?" Kritik 200 (2011): 26-35; e depois em tradução para o italiano por Carlo Penco, "Epistemologia: Chi Ne Ha Bisogno?" Epistemologia XXXI (2011): 269-88. A presente tradução foi feita por Tiago Oliveira a partir do texto em inglês disponível em Haack, Susan (2015) "Epistemology: Who Needs It?", Kilikya Felsefe Dergisi, (3) pp.1-15. Tradução e publicação gentilmente autorizadas pela autora.

2 Doutor em Filosofia pela Universidade Federal de Minas Gerais (UFMG), Belo Horizonte - MG, Brasil. Professor do Colégio Pedro II (CP II), Niteroi - RJ, Brasil.

3 Donald Rumsfeld (secretário de defesa do presidente George W. Bush), Department of Defense news briefing, 12 de fevereiro de 2002. [N.T.: Em inglês, a afirmação é ainda mais confusa, pois lança mão de expressões como "known knowns", algo que soa como "conhecidos conhecidos", "known unknowns", "desconhecidos conhecidos" e "unknown unknowns", "desconhecidos desconhecidos".]

4 "Rumsfeld's Unknown Unknowns Take Prize," http://www.buzzle.com.editorials/12-1-03-48150.asp (último acesso em 4 de janeiro de 2011). Schwarzenegger era então o governador da Califórnia, Patten um ex-presidente recente do Partido Conservador Britânico.
}

HAACK, Susan. Epistemologia: quem precisa dela? Tradução de Tiago Luís Teixeira de Oliveira. Griot : Revista de Filosofia, Amargosa - BA, v.19, n.2, p.330-342, junho, 2019. 
quanto seus proponentes dão a entender - e sendo assim, por que tantas pessoas desconfiam da ideia; ou que lições tirar da revelação de que o cientista médico, que espalhou pânico sobre supostos danos da vacina SCR (sarampo, caxumba e rubéola), tinha falsificado seus resultados, ou que os cientistas climáticos da corrente dominante tentaram suprimir o trabalho que divergia da visão majoritária; etc., etc. Logo veremos o porquê.

Em 1843, John Stuart Mill escreveu que "[a] tarefa do magistrado, do comandante militar, do médico, do agricultor, é meramente a de julgar a evidência, e agir consistentemente com o que a evidência sugere."5 Ele está certo. De fato, todos nós precisamos "julgar a evidência, e agir adequadamente" - ao decidir o que comer, em quem confiar, se vamos submeter-nos a um tratamento médico sugerido, etc. Não podemos agir com segurança ou eficiência a menos que tenhamos alguma ideia do que provavelmente ocorre se fizermos isto ou aquilo; o que requer seguir tanta evidência quanto tivermos, ou pudermos obter. Frequentemente, também, precisamos considerar as fontes da nossa evidência, e a possibilidade de que ela tenha sido empobrecida ou distorcida ao ser transmitida; e distinguir bem o que seria investigação malconduzida - e esforços de boa-fé para descobrir a verdade -, do que seriam tentativas de minimizar um escândalo ou enquadrar um suspeito conveniente.

Nossa assim chamada "Era da Informação" é marcada, não só pelo crescimento da dependência de meios eletrônicos e dispositivos para disseminação de informação, mas também pela inundação sem precedentes de informação mesma; e por um crescente senso de que políticas sociais - sobre o meio ambiente, a economia, a saúde pública, a educação, o sistema de justiça, as relações internacionais, etc. deveriam ser baseadas no conhecimento de seus benefícios e seus custos. É de fato desejável que decisões sociais, assim como as individuais, sejam informadas pelo que quer que possamos descobrir sobre as consequências prováveis de se fazer isto ou aquilo - ou de não fazer nada. Não podemos esquecer, entretanto, de que a informação factual sozinha não pode nos dizer quais políticas adotar: uma coisa é dizer quais custos e benefícios existem ao represar este rio, ao elevar a taxa de imposto em $10 \%$, ao exigir vacinação de todas as crianças para esta doença, ou etc., outra coisa é dizer se os benefícios superam os custos. (Análises formais de custobenefício, que inevitavelmente pressupõem juízos avaliativos em identificar fatores relevantes, atribuindo-lhes peso, não conseguem fechar a lacuna ${ }^{6}$. Nem devemos esquecer que adquirir informação demanda esforço e, frequentemente, dinheiro; ou que, à medida que o apetite por informação cresce, não somente mais e mais informação, mas também mais e mais desinformação tornam-se disponíveis; e que não só mais e mais pesquisa é conduzida, mas também mais e mais pseudopesquisa. Isso torna cada vez mais difícil separar coisa boa de lixo.

\footnotetext{
${ }^{5}$ John Stuart Mill, A System of Logic, Ratiocinative and Inductive, Being a Connected View of the Principles of Evidence and the Methods of Scientific Investigation (1843), 8th ed., London, 1970, p. 5

${ }^{6}$ Veja Lawrence Tribe, "Policy Science: Analysis or Ideology?" In: Philosophy and Public Affairs, 21, 1972: 66110.
}

HAACK, Susan. Epistemologia: quem precisa dela? Tradução de Tiago Luís Teixeira de Oliveira. Griot : Revista de Filosofia, Amargosa - BA, v.19, n.2, p.330-342, junho, 2019. 
Alguns - talvez desiludidos por quão comum seja a pseudoinvestigação, e por quão frequente as afirmações construídas de modo confiante se mostraram falsas professam ter perdido completamente a confiança em conceitos como evidência, verdade, investigação, etc. Richard Rorty, um deles, diz que "não possu[i] muito uso para a noção de "verdade objetiva," " 7 e vê "racionalidade como civilidade, ... respeito pelas opiniões daqueles que o cercam, ... [e] 'verdade' como uma palavra que se aplica àquelas crenças sobre as quais podemos concordar". ${ }^{8}$ Mas quando é preciso decidir sobre um tratamento médico, escolher um voo, ou ligar para o banco para ter certeza de que o cheque da editora foi depositado, assim como qualquer um, Rorty e seus companheiros cínicos se orientam pela evidência que podem obter - revelando que não acreditam de fato, como professam, que a (tal como dizem) "assim chamada "verdade", "assim chamada "evidência", etc., são pura convenção social, sem base objetiva.

A disciplina para a qual compete articular o que distingue investigação genuína da pseudoinvestigação, o que torna a pesquisa mais ou menos bem conduzida, a evidência mais forte ou mais fraca, etc. é a teoria filosófica do conhecimento, conhecida entre os profissionais da área como "epistemologia" - uma palavra sem charme e sem atrativos para uma empreitada que é tantas vezes, receio, sem charme e sem atrativos. (Como observou o jornalista Jonathan Rauch, em um livro afiado sobre códigos de discurso do campus, "[s]e você quer esvaziar a sala numa festa de coquetel," tudo que precisa fazer é dizer "epistemologia".) ${ }^{9}$ Entretanto, se você quiser entender práticas tão vitais como julgar o valor da evidência e a qualidade da investigação, é de epistemologia que você precisa.

Eu não tenho a intenção de sugerir que todo mundo precisa de uma teoria epistemológica simplesmente para se ocupar de seus afazeres diários. Aqui está Mill de novo: "a [h] umanidade julgou pela evidência, e o fez corretamente com frequência, antes que [a epistemologia] fosse uma ciência, ou nunca poderiam ter criado uma. "10 Novamente, ele está certo. Usualmente podemos julgar o valor da evidência suficientemente bem sem dar a isso muito pensamento fundamentado, ou sem precisar de qualquer teoria epistemológica. Mas tal teoria pode ser genuinamente de grande ajuda quando a evidência é complexa ou ambígua, ou o quando o assunto em questão é tão emocionalmente influenciado que corremos o risco de perder a calma - como ocorre sempre em tribunais de direito, em política, em problemas médicos e de saúde pública, em questões ambientais e, sim, em matéria de inteligência militar.

Também não quero dar a entender que somente o trabalho de epistemólogos profissionais pode ser útil; há intuições epistemológicas no trabalho de acadêmicos do direito, historiadores, e cientistas, etc.: por exemplo, a observação aguçada do matemático W.K. Clifford de que "o homem crédulo é o pai da mentira e do

\footnotetext{
${ }^{7}$ Richard Rorty, "Trotsky and the Wild Orchids," Common Knowledge, 1.3, 1992: 140-53, p. 141.

${ }^{8}$ Richard Rorty, "Science as Solidarity," In: John S. Nelson, Allan Megill, and Donald M. McCloskey, eds, The Rhetoric of the Human Sciences, Madison, WI, 1987, 38-52, pp. 44, 40, 45.

9 Jonathan Rauch, Kindly Inquisitors: The New Attacks on Free Thought, Chicago, 1993, p. 35.

10 Mill, System of Logic (note 3), p. 6. (A palavra que Mill utiliza não é "epistemologia", que naquele tempo não havia se tornado moeda corrente, mas "lógica", que tal como seu subtítulo indica, era então usada num sentido muito mais lato que atualmente, para incluir o que seria hoje chamada de "epistemologia".)
}

HAACK, Susan. Epistemologia: quem precisa dela? Tradução de Tiago Luís Teixeira de Oliveira. Griot : Revista de Filosofia, Amargosa - BA, v.19, n.2, p.330-342, junho, 2019. 
engano"11; e o comentário instigante do físico Percy Bridgman de quando "o homem [com] alguma apreciação e capacidade para integridade intelectual" pensa sobre nossas instituições sociais, sua "reação inevitável será obviamente um completo repúdio em sua própria mente dos disparates que é convidado a aceitar."12 Há intuições epistemológicas, também, nas obras de ficção: por exemplo, em Erros irreversíveis $^{13}$ de Scott Turow, onde um advogado de defesa apelando a um último recurso contra a pena de morte descobre nova evidência que faz com que a culpa de seu cliente pareça cada vez mais provável - até que ele encontra uma peça fundamental de evidência que revela que todo o resto fora enganoso; em Headlong, ${ }^{14}$ de Michael Frayn, onde um professor de filosofia desesperadamente tenta descobrir se a pintura que espera comprar por uma pechincha de seu vizinho desavisado é, como acredita num primeiro momento, um inestimável Bruegel perdido, descobre evidência que parece mostrar que sim, é - não, não é - sim, é,...e assim por diante; e em Remédio Amargo, ${ }^{15}$ de Arthur Hailey, onde um cientista médico quer tanto acreditar que sua nova droga é uma importante descoberta que se sente justificado em esconder os primeiros sinais da evidência de efeitos colaterais perigosos.

Também não quero dar a entender que todo trabalho de epistemólogos profissionais será útil para "o magistrado, o comandante militar, o médico" ou o restante de nós, à medida em que lutamos com a evidência complexa ou perturbadora. Como sugeri antes, muito do trabalho contemporâneo em epistemologia é hermético e autoabsorvido; de qualquer modo, o trabalho de definir "conhecimento" ou a refutação do ceticismo, ou abordagens (como o confiabilismo ou epistemologia da virtude) que derrubam o papel da evidência, pouco ajudam nas questões que nos afligem aqui no mundo real. ${ }^{16} \mathrm{O}$ que precisamos é de uma teoria epistemológica direcionada a problemas centrais sobre a investigação, a evidência, etc. soletrada em detalhe suficiente para lidar com evidência de séria complexidade; e, ao menos aproximadamente - bem, verdadeira.

Como Nicholas Rescher uma vez observou, "se duas pessoas concordam, uma delas não é um filósofo". ${ }^{17}$ Ele exagera; mas nem tanto. O que eu ofereço aqui não será a perspectiva epistemológica, mas a minha perspectiva sobre uma bateria de questões epistemológicas chave: sobre a diferença entre pseudoinvestigação e a coisa real, sobre a evidência e a qualidade da evidência, sobre como a informação é transmitida e pode ser distorcida, e sobre a opinião especializada.

\footnotetext{
11 W. K. Clifford, "The Ethics of Belief" (1876) In: Timothy J. Madigan, ed., The Ethics of Belief and Other Essays, Amherst, NY, 1999, 70-96, p. 77. Veja também Susan Haack, "Credulity and Circumspection: epistemological Character and the Ethics of Belief," Proceedings of the American Catholic Philosophical Association (2015): 1-21. [N.T.: O artigo de Clifford recebeu uma tradução portuguesa em Desidério Murcho(org). A ética da crença. Trad. Vitor Guerreiro. Lisboa: Ed. Bizâncio, 2010.]

12 Percy W. Bridgman, "The Struggle for Intellectual Integrity" (1933). In: Bridgman, Reflections of a Physicist, New York, 1955, 361-79, p. 368

13 Scott Turow, Reversible Errors, New York, 2002. [N.T.: O livro recebeu uma edição em português sob o título de Erros irreversíveis. Trad. Alves Calado. Rio de Janeiro: ed. Bestbolso, 2012.]

14 Michael Frayn, Headlong, London and New York, 1999.

${ }^{15}$ Arthur Hailey, Strong Medicine, London, 1984. [N.T.: O livro recebeu uma edição em português sob o título de Remédio amargo. Trad. A.B. Pineiro de Lemos. Rio de Janeiro: ed. Record, 1984.]

16 "Epistemologia social" é a moda do momento; mas até onde posso dizer, ainda não há aqui, como tal, um corpo bem desenvolvido de teoria.

${ }_{17}$ Nicholas Rescher, The Strife of Systems, Oxford, 1985, p. 3.
}

HAACK, Susan. Epistemologia: quem precisa dela? Tradução de Tiago Luís Teixeira de Oliveira. Griot : Revista de Filosofia, Amargosa - BA, v.19, n.2, p.330-342, junho, 2019. 
A investigação genuína é uma tentativa de descobrir a verdade de alguma questão. Isso não significa que cientistas, historiadores, etc., procuram A Verdade, num sentido semirreligioso, mas que, por exemplo, um historiador que investiga se Thomas Jefferson foi o pai das crianças escravas de sua casa queira terminar por concluir que Jefferson era o pais dessas crianças somente no caso em que ele fosse pai delas, e que ele não era se não fosse (e que é um pouco mais complicado do que isso se for um pouco mais complicado que isso); ${ }^{18}$ que um cientista investigando o aquecimento global acabe por concluir que o aquecimento global é produto humano somente no caso de o aquecimento global ser produto humano, e que não é se não for (e, etc.); e assim por diante.

Um investigador sério procurará toda evidência que puder, e fará seu melhor para avaliar se ela garante esta conclusão ou aquela, ou se ela é insuficiente para garantir qualquer conclusão que seja. Mas alguém que já sabe qual conclusão quer encontrar, e está procurando por evidência que a suporte - e por maneiras de disfarçar ou derrubar a evidência em contrário - não está realmente investigando; pois é parte do significado da palavra "investigar" que não se saiba o que vai dar. ${ }^{19} \mathrm{E}$ por isso que, quando um governo ou nossa universidade lança uma Investigação Oficial sobre um escândalo perturbador, alguns de nós - suspeitando que tal "investigação" vai levar a uma conclusão desejada, reconfortante não importa qual a evidência - lançamos mão de nossas aspas assustadas [scare quotes]. ${ }^{20}$

Sem dúvida, as motivações das pessoas são geralmente misturadas, daí haver um continuum em casos intermediários onde o que está havendo nem é investigação pura, desinteressada, nem um simulacro: e.g.: um estudioso que obteve uma bolsa com base em uma descrição ultraotimista das conquistas a serem obtidas em seu projeto, e falsifica seu relatório para evitar colocar em risco suas chances de arrecadar dinheiro em futuras bolsas; um cientista cujas anotações inadequadas lhe fizeram esquecer da evidência inconveniente que sua hipótese não consegue explicar; ${ }^{21}$ ou um detetive cuja suspeita concentrou-se prematuramente em um único suspeito, e que dá de ombros para a evidência capaz de apontar para outros.

Alguém que precise desesperadamente do dinheiro pode se convencer de que tem uma boa chance de ganhar na loteria; alguém que teme fortemente que a verruga que apareceu no seu nariz seja cancerígena pode se convencer de que aquilo parece pior do que realmente é. Mas a esperança não pesa na probabilidade de que o bilhete seja premiado, nem o medo na probabilidade de que a verruga seja maligna; nossos desejos, esperanças, e medos podem afetar nosso julgamento sobre a evidência, mas eles, em si mesmos, não são evidências. Evidência consiste, antes, naquilo que vemos, ouvimos, etc. (evidência experiencial) e informação de fundo

${ }^{18}$ A evidência do DNA indica que algum homem da família Jefferson era o pai de uma daquelas crianças. William G. Hyland, In Defense of Thomas Jefferson: The Sally Hemings Sex Scandal, New York, 2009.

${ }^{19}$ Veja Susan Haack, "Confessions of an Old-Fashioned Prig" e "Preposterism and Its consequences," In: Haack, Manifesto of a Passionate Moderate: Unfashionable Essays, Chicago,1998, 7-30, 88-208.[N.T.: Há uma tradução do livro no Brasil sob o título de Manifesto de uma moderada apaixonada: ensaios contra a moda irracionalista. Trad. Rachel Herdy. Rio de Janeiro: Ed. PUC-Rio: Ed. Loyola, 2011].

20 "Scare quotes" é o nome em inglês para a utilização das aspas como modo de indicar ao leitor que o termo está sendo empregado com ironia ou fora de seu sentido convencional. [N.T.]

${ }^{21} \mathrm{Um}$ estudo relata que mais de $27 \%$ dos cientistas entrevistados admitiram manter registros inadequados. Brian C. Martinson et al., "Scientists Behaving Badly," Nature, 435.9, 2005: 737-8.

HAACK, Susan. Epistemologia: quem precisa dela? Tradução de Tiago Luís Teixeira de Oliveira. Griot : Revista de Filosofia, Amargosa - BA, v.19, n.2, p.330-342, junho, 2019. 
(razões); que, como argumentei em Evidence and Inquiry (Evidência e investigação), ${ }^{22}$ trabalham juntos mais como pistas e entradas já preenchidas de palavras cruzadas.

A evidência pode ser melhor ou pior; se, e neste caso, em que grau uma afirmação é garantida, depende de quão boa é a evidência em relação àquela afirmação. Razões ramificam, como entradas de palavras cruzadas; e o que faz uma evidência melhor ou pior é análogo ao que faz uma entrada de palavra cruzada mais ou menos razoável: quão sustentadora (supportive) ela é (análogo: quão bem uma entrada se encaixa com suas pistas e as entradas já preenchidas); quão segura ela é, independente da afirmação em questão (quão razoáveis as entradas já preenchidas são); e quão compreensiva ela é, quanta evidência relevante ela inclui (quanto das palavras cruzadas foram preenchidas). Como essa terceira condição revela, se sua evidência é muito rudimentar, você não tem direito de acreditar nela de qualquer maneira - por isso é, sem dúvida, que a palavra inglesa "parcial" tem dois significados: "incompleto" e "tendencioso". Como isso também mostra, não possuirmos evidência de que $p$ não significa possuirmos evidência de que não-p.

A relevância ou irrelevância da evidência para uma afirmação depende de fatos sobre o mundo. Caso o caráter realmente seja revelado pela escrita à mão, o modo como uma pessoa escreve a letra "g" deve ser relevante para ela ser ou não honesta; caso contrário, não. Caso os ratos sejam como seres humanos nos aspectos relevantes, o efeito que uma droga tem sobre eles é relevante para o efeito que ela terá em humanos; caso contrário, não. (Talidomida foi testada em ratas grávidas sem efeitos negativos nelas, ou em suas proles; mas, apesar de seus efeitos altamente sedativos em humanos, tal efeito não ocorreu em ratos. Talvez se - ao invés de planejar novos testes para mostrar que os ratos estavam, na verdade, um pouco sedados - eles tivessem questionado se haveria alguma diferença fisiológica relevante entre ratos e humanos, a tragédia da Talidomida pudesse ser evitada). ${ }^{23}$ Repetindo: julgar a qualidade da evidência requer conhecimento factual.

Além do mais, nossa evidência é frequentemente de segunda mão: ${ }^{24}$ e.g., quando escolho um voo baseado na informação que um representante da empresa aérea me dá; quando um cientista chega a uma conclusão usando instrumentos complicados, ou confiando em observações ou cálculos estatísticos de outras pessoas, etc.; ou quando um médico prescreve um tratamento confiando em resultados publicados em periódicos médicos, ou sobre o que um representante de companhia farmacêutica lhe diz sobre os usos de um remédio além do rótulo. Raramente pensamos sobre isso a menos que tenhamos medo de ter sido enganados; mas todos dependemos implicitamente de afirmações sobre quão confiáveis são essas máquinas, instrumentos, ou pessoas, quão bem-sucedido aquele periódico científico é em selecionar trabalhos confiáveis, quão provável é que um representante de empresa farmacêutica diga toda a verdade sobre os benefícios e efeitos colaterais de um produto rentável, ou que um representante de empresa aérea procure por todos os voos disponíveis, etc. Não podemos passar sem confiar na evidência transmitida por outros, assim não podemos evitar a necessidade, não só de julgar o quanto é provável

${ }^{22}$ Susan Haack, Evidence and Inquiry (1993); 2nd, expanded ed., Amherst, NY 2009.

23 A história trágica é contada em Trent D. Stephens and Rock Brynner, Dark Remedy: The Impact of Thalidomide and Its Revival as a Vital Medicine, Cambridge, MA, 2001.

${ }^{24} \mathrm{Os}$ aspectos sociais da teoria apresentados em Evidence and Inquiry (nota 19) são desenvolvidos no meu Defending Science—Within Reason: Between Scientism and Cynicism, Amherst, NY, 2003, capítulo 3.

HAACK, Susan. Epistemologia: quem precisa dela? Tradução de Tiago Luís Teixeira de Oliveira. Griot : Revista de Filosofia, Amargosa - BA, v.19, n.2, p.330-342, junho, 2019. 
de que eles estejam nos dizendo a verdade tal como acreditam, mas também de avaliar quão adequadamente eles julgam a evidência que eles possuem.

Mesmo nas sociedades mais primitivas, as pessoas confiam nas notícias de outrem sobre o melhor lugar para encontrar diversão ou cruzar um rio, sobre conhecimento transmitido de uma geração para a seguinte acerca de propriedades medicinais das plantas, etc. E nas complexas sociedades modernas somos muitas vezes obrigados, não simplesmente a depender da evidência transmitida por outrem, mas a confiar na opinião de especialistas sobre questões arcanas sobre as quais sabemos muito pouco para julgar por nós mesmos. Se você não estiver familiarizado com o vocabulário relevante, ou não sabe os fatos relevantes, então, - tal qual um falante monoglota da língua tagalog tentando avaliar a razoabilidade de uma entrada em uma palavra cruzada em inglês, na qual todas as pistas são retiradas das peças de Shakespeare - você simplesmente não pode julgar se, ou em que grau, a evidência garante uma conclusão. É por isso que nos esforçamos para distinguir especialistas reais de pseudoespecialistas plausíveis, mas não confiáveis, recaindo em falíveis medidas substitutivas como o prestígio da instituição de onde o suposto especialista recebeu seu título ou do jornal no qual seu trabalho foi publicado.

Mas apesar da complexidade da vida moderna, nós humanos ainda somos bem, humanos. Quando precisamos lidar com questões difíceis, é sempre tentador buscar atalhos; e mesmo com a melhor das intenções do mundo pode ser muito difícil entender para onde uma evidência complexa ou ambígua aponta. E como Denis Diderot há muito tempo nos lembrou, o homem é feito "de força e fraqueza, de visão e cegueira, de pequenez e grandeza". ${ }^{25} \mathrm{Sim}$, somos capazes de feitos cognitivos notáveis - mas tantas vezes somos preguiçosos, e pulamos para as conclusões; tantas vezes somos tendenciosos, e ignoramos ou esquecemos convenientemente da evidência que aponta para fatos que consideramos impalatáveis; e tantas vezes nos apoderamos da evidência inadequada que confirme nossos temores ou sirva a nossos interesses.

Cientistas, também, são apenas humanos, com as mesmas fraquezas e limitações perceptuais e cognitivas que o resto de nós, e as mesmas tendências de tomar atalhos e pensar a partir de seus desejos ou temores. Ao longo do tempo, entretanto, as ciências desenvolveram ferramentas para superar limitações perceptuais e cognitivas - telescópios, microscópios, técnicas matemáticas e estatísticas, métodos de simulação por computadores, etc.; e mecanismos sociais internos por meio dos quais a comunidade de cientistas naturais, ao menos, tem conseguido manter a maioria de seus membros, a maior parte do tempo, razoavelmente honesta - um ethos que recompensa conquistas reais, encoraja o compartilhamento de evidências, e desencoraja a trapaça, bem como mais mecanismos formais como o processo de revisão por pares para distribuir fundos de pesquisa e triar publicações. ${ }^{26}$

Mas enquanto aquelas ferramentas técnicas das ciências geralmente se tornam cada vez melhores, os mecanismos sociais em manter cientistas honestos não; na verdade, eles agora estão sob tensão severa na medida em que os cientistas se

25 Denis Diderot, Addition aux pensées philosophiques (c. 1762), in The Oxford Book of Aphorisms, ed.John Gross, Oxford, 1983, pp. 24-5

26 Veja Defending Science (note 21) capítulo 4.

HAACK, Susan. Epistemologia: quem precisa dela? Tradução de Tiago Luís Teixeira de Oliveira. Griot : Revista de Filosofia, Amargosa - BA, v.19, n.2, p.330-342, junho, 2019. 
encontram cada vez mais pressionados com urgência a ganhar financiamentos, a publicar, etc. E a tensão é pior precisamente onde o trabalho científico envolvido é do maior interesse público: e.g., na ciência climática e nas ciências médicas - onde as notícias da mídia se aproveitam de resultados científicos interessantes, mas omitem importantes ressalvas e limitações, e políticos se aproveitam daquelas reportagens para angariar apoio para suas políticas. É pouco surpreendente que alguns cientistas sucumbam à tentação de falsificar, exagerar e mesmo inventar. ${ }^{27}$

Muito do trabalho científico que lemos na imprensa é altamente especulativo, e provavelmente não vai dar em nada; e em muitas questões a opinião científica ainda não está formada. Frequentemente superestimamos o quão bem entendemos a evidência complexa, arcana, e pulamos para conclusões não garantidas; ou subestimamos o que podemos descobrir se tentarmos, e desistimos por desespero, humildemente aceitando o que quer que o pretenso especialista nos diga. Mas quando há controvérsia científica não resolvida em um campo não familiar, a resposta razoável é reconhecer que você não está autorizado a uma opinião; e, por contraste, quando um estudo médico, para exemplificar, foi baseado não nos diagnósticos de médicos, mas nos relatos dos próprios pacientes sobre o que estava errado com eles, você não precisa ser um especialista para detectar problemas.

Aqui está Mill mais uma vez: "[a epistemologia] não fornece...as provas, mas ensina o que faz com que elas sejam provas, e como julgá-las". ${ }^{28}$ Novamente, ele está certo; teorias epistemológicas podem nos dizer o que torna uma evidência melhor ou pior, mas não se uma afirmação é garantida, e em que grau, ou se um estudo científico é metodologicamente falho. Um curso intensivo em epistemologia não vai transformar magicamente você em um especialista de tudo, nem habilitar você a julgar a evidência arcana, detectar falhas de planejamento técnico num estudo científico, ou separar especialistas confiáveis de não confiáveis em um campo não familiar. Mas (boa) epistemologia pode ajudar você a entender o que vai mal quando seus esforços em avaliar a evidência dão errado, quando você confunde um charlatão ou um inteligente auto-promotor com um investigador sério, etc.

Como vimos, há muitas maneiras de cair em armadilhas epistemológicas: interpretando mal o que é evidência, ou o que é relevante para o quê, concentrando na evidência disponível e esquecendo sobre outras evidências potencialmente relevantes que não possuímos; julgando mal o quão bem a evidência que temos garante a conclusão, talvez por permitir que nossos desejos ou nossos temores influenciem nosso julgamento; falhando em perceber que informação foi perdida ou distorcida no processo de transmissão, ou que aqueles nos quais confiamos permitiram que seus julgamentos sobre o peso da evidência fossem influenciados por suas esperanças ou temores; ou simplesmente ao ser relutante em admitir que estávamos enganados, ou que simplesmente não sabemos.

Com tais pensamentos em mente, eu volto àquele artigo recente de um periódico britânico de medicina, The Lancet, argumentando haver evidência empírica

${ }^{27}$ Id., capítulo 7.

28 Mill, System of Logic (nota 3), p. 5.

HAACK, Susan. Epistemologia: quem precisa dela? Tradução de Tiago Luís Teixeira de Oliveira. Griot : Revista de Filosofia, Amargosa - BA, v.19, n.2, p.330-342, junho, 2019. 
para alocar recursos médicos escassos em adolescentes e jovens ao invés de crianças e pessoas mais velhas. ${ }^{29}$ Ao ler o próprio artigo (no lugar de reportagens da mídia), você logo entende que a tal "evidência" consiste de questionários mostrando que $a$ maioria das pessoas pensa ser este o modo como tais recursos devem ser alocados. Mas a informação sobre o que a maioria das pessoas pensa ser o melhor possivelmente não é capaz de nos dizer o que é o melhor. E de qualquer modo, cavando um pouco mais fundo, você logo descobre que essa suposta evidência está longe de ser segura: apenas dois estudos são citados; um não está publicado, e nenhum deles diz exatamente o que os autores do artigo do Lancet afirmam.

Que dizer sobre "medicina baseada em evidência"? Isso certamente soa como uma coisa boa - quem não preferiria saber, antes de tomar um remédio qualquer, que tal remédio irá fazer bem, e que não matará ninguém no processo? De fato, medicina baseada em evidência é uma coisa boa - caso "baseada em evidência" signifique "levar em conta toda a evidência relevante que temos ou podemos obter". Mas as coisas não vão bem quando secretamente se transmuta a ideia totalmente razoável de que devemos preferir tratamento médico em que há evidência de que seja tanto efetivo quanto seguro pela ideia muito menos razoável de que devemos preferir tratamentos médicos apoiados por um tipo limitado de evidência - estudos epidemiológicos e pesquisas clínicas. Isso é a clássica propaganda enganosa: primeiro apela para nosso senso de que a evidência importa, e então secretamente permite apenas a evidência de certos tipos preferidos.

Evidência epidemiológica e pesquisa clínica não são as únicas evidências relevantes para estimar o valor de um tratamento médico. A informação sobre, por e.g., os efeitos de uma droga sobre animais também é relevante; tanto como são as observações de médicos sobre quais pacientes respondem bem a um tratamento, e quais mal ou nem tanto - que podem, com a evidência de variações individuais possivelmente relevantes, complementar a evidência sobre categorias mais amplas de pessoas em relação aos estudos epidemiológicos e à pesquisa clínica. E estudos epidemiológicos e pesquisas clínicas não são sempre boa evidência, também, mas podem ser falhos no projeto, na execução, ou em ambos. $O$ único estudo epidemiológico que sugere que o implantes de seios de silicone causam distúrbios no tecido conjuntivo dependeu totalmente dos relatos das próprias mulheres sobre seus (supostos) problemas médicos; ${ }^{30} \mathrm{O}$ teste VIGOR, com base no qual a Merck conseguiu da FDA ${ }^{31}$ aprovação para comercializar Vioxx, sua droga para artrite que é sucesso de vendas, foi planejado para registrar os efeitos gastrointestinais da droga, que a empresa tinha razões para pensar que seriam benéficos, por mais tempo do que ele registrou efeitos cardiovasculares ${ }^{32}$ - efeitos que subsequentemente se provaram tão ruins que a droga precisou ser retirada de circulação.

29 Govind Persad, Alan Wertheimer, e Ezekiel J. Emmanuel, "Principles for Allocation of Scarce Medical Resources," The Lancet, 373, 2009: 432-32

30 Charles H. Henneckens et al., "Self-Reported Breast Implants and Connective Tissue Diseases in Female Health Professionals," Journal of the American Medical Association, 275, 1996: 616-621.

${ }^{31}$ Food and Drug Administration (Administração para Alimentos e Drogas), a agência reguladora que determina se uma droga ou um aparelho medicinal se comprova segura(o) e efetiva(o), e pode ser vendida(o) nos EUA.

32 Claire Bombadier et al., "Comparison of upper Gastrointestinal Toxicity of Rofecoxib [Vioxx] and Naproxen in Patients with Rheumatoid Arthritis," New England Journal of Medicine, 343.21, 2000: 1520-28. David Armstrong, "How the New England Journal Missed Warning Signs on Vioxx: Medical Journal Waited Years to Report Flaws in Article that Praised Pain Drug," Wall Street Journal, 11 May 2006, A1, A11.

HAACK, Susan. Epistemologia: quem precisa dela? Tradução de Tiago Luís Teixeira de Oliveira. Griot : Revista de Filosofia, Amargosa - BA, v.19, n.2, p.330-342, junho, 2019. 
Um médico atarefado, se simplesmente não confia no que os representantes de empresa farmacêutica lhe dizem, provavelmente lê, no máximo, os resumos dos artigos de periódicos médicos; e pode simplesmente assumir que o processo de revisão por pares fará a triagem dos trabalhos fracos. ${ }^{33}$ Mas os pareceristas da altamente prestigiada New England Journal of Medicine, onde o relatório do teste VIGOR apareceu, não notaram a falha em seu planejamento; nem, depois, os outros pareceristas repararam que o autor do estudo APROVe, com base na qual a droga fora banida, não usou realmente os métodos estatísticos que afirmaram usar. ${ }^{34} \mathrm{E} o$ exemplo do implante de seios ilustra o que ocorre quando a avaliação da evidência é influenciada pelo medo: um programa televisivo líder de audiência levou muitas mulheres com implantes de silicone a se preocupar com que a menor pontada fosse o primeiro sinal de um problema sério; e advogados logo começaram a ganhar, assinando cláusulas de segurança para clientes de implantes de seios. ${ }^{35}$

O imbróglio sobre a vacina SCR e o autismo é até mais perturbador. Em 1998, um artigo aterrorizante em The Lancet do Dr. Andrew Wakefield et al. sugeriu que aquela vacina poderia causar uma nova síndrome de doença intestinal e autismo. $^{36}$ A imprensa logo levantou o relato; muitos pais ficaram receosos de vacinar suas crianças; e a proporção de sarampo e outras doenças infantis evitáveis aumentou. ${ }^{37}$ Mas deveria ter ficado claro até para um leitor leigo que o estudo do Dr. Wakefiels era falho: não havia grupo de controle; o estudo era baseado em apenas doze crianças - oito das quais (afirmou Wakefield) desenvolveram autismo depois da vacinação de SCR; e ele dependia daquilo que os pais podiam se lembrar sobre quando os sintomas de suas crianças apareceram primeiro. Os críticos logo apontaram esses e outros defeitos; e novos estudos epidemiológicos falharam em encontrar qualquer correlação entre a vacina e o autismo. ${ }^{38}$

Em 2004, o jornalista investigativo Brian Deer notou o envolvimento de Wakefield com advogados para que os pais processassem produtores de vacinas, e sugeriu que seu estudo violara normas éticas. ${ }^{39}$ O Conselho Médico Geral (GMC: o corpo que regula a profissão médica no Reino Unido) iniciou uma investigação. E então, outra sacudida: no decorrer das audiências de ética, as fichas médicas das crianças foram colocadas a público; e Deer descobriu que em todos os doze casos havia discrepâncias significativas entre as gravações das crianças e as descrições de Wakefield: e.g., algumas das crianças mostraram sinais de autismo antes que fossem

\footnotetext{
33 Sobre o sistema de revisão por pares em geral, veja Haack, "Peer Review and Publication: Lessons for Lawyers," Stetson Law Review, 36.3, 2007: 789-819.

${ }^{34}$ Heather Won Tesoriero, "Vioxx Correction May Add Pressure to Merck's Defense," Wall Street Journal, 27 de junho de 2006, p. A2. Veja também o meu "The Integrity of Science: What It Means, Why It Matters" (2006), in Putting Philosophy to Work: Inquiry and its Place in Culture, Amherst, NY, 2008, pp. 95-127.

35 Veja Marcia Angell, Science on Trial: The Clash of Medical Evidence and the Law in the Breast Implant Case, New York, 1996.

36 Andrew Wakefield et al., "Ileal-lymphoid-nodular Hyperplasia, Non-specific Colitis, and Pervasive Developmental Disorder in Children," The Lancet, 351, February 28th, 1998: 637-41.

37 Editors of the British Medical Journal, "Wakefield Article Linking MMR Vaccine and Autism was Fraudulent," British Medical Journal, 342, 2011: 64-6. (A incidência de sarampo aumentou de forma significativa no Reino Unido e nos EUA; não sei o que ocorreu em outros lugares).

${ }^{38} I d$.

39 Brian Deer, "Revealed: MMR Research Scandal," Times Online (London), 22 de fevereiro de 2004, http://www.timesonline.co.uk/tol/life_and_style/health/article1027636.ece (último acesso em 27 de janeiro de 2011).
}

HAACK, Susan. Epistemologia: quem precisa dela? Tradução de Tiago Luís Teixeira de Oliveira. Griot : Revista de Filosofia, Amargosa - BA, v.19, n.2, p.330-342, junho, 2019. 
vacinadas, e outras sequer tinham autismo. ${ }^{40} \mathrm{Em}$ suma, o trabalho de Wakefield parece não só ter sido falho, mas fraudulento. Em 2010, o GMC proibiu Wakefield de praticar medicina no Reino Unido, ${ }^{41} \mathrm{e}$ The Lancet fez a retratação de seu artigo. ${ }^{42}$

Os doze outros cientistas médicos cujos nomes apareceram no artigo de Wakefield como coautores - talvez super ansiosos de aumentar seus currículos emprestaram sua autoridade para uma versão final de artigo que, de fato, Wakefield escreveu sozinho; e Robin Horton, o editor de The Lancet, estava aparentemente tão ansioso por fazer barulho: quatro dos seis revisores alertaram-no para rejeitar o artigo de Wakefield, mas ele o aceitou mesmo assim, considerando-o "provocativo". ${ }^{43}$ A saga Vioxx nos recorda de que o processo de revisão por pares é um mecanismo de controle de qualidade bastante falível; a saga da vacina SRC nos recorda de que nem todo trabalho publicado em periódicos revisados por pares passou de fato pelo escrutínio dos revisores - e que nem todos os "autores" de um artigo podem saber o que de fato este contém.

E quando - o último exemplo para o qual tenho espaço - há o fiasco conhecido nos E.U.A. como "Climategate". ${ }^{44}$ Aqueles de nós das humanidades e das ciências sociais estão dolorosamente cientes de que em nossas áreas a revisão por pares pode ser incompetente, distorcida pela influência de panelinhas, ou mesmo completamente corrupta. Para nós, a descoberta de milhares de e-mails de cientistas do clima bem-estabelecidos conspirando para excluir os trabalhos dos dissidentes dos periódicos científicos, ${ }^{45}$ apesar de muito desapontador, não foi totalmente um choque. O processo de revisão por pares em ciências é, provavelmente, um mecanismo de controle de qualidade um pouco melhor do que, digamos, o processo de revisão por pares em filosofia, mas também é muito vulnerável à corrupção; e o perigo é mais aguçado em uma área onde as paixões correm soltas, como ocorre na ciência climática.

Seguramente, a ocorrência de esforços para suprimir o trabalho desviante da visão predominante de alarme global e suas causas não mostra que tal visão é falsa. Nem, tampouco, o fato de que várias investigações ${ }^{46}$ (ou talvez "investigações") ${ }^{47}$ dentro do caso chegaram às conclusões tranquilizadoras mostra que a visão predominante é verdadeira. Eu lutei com um artigo de um professor de meteorologia do Instituto de Tecnologia de Massachusetts: "o potencial...para alarme entra com o problema da sensibilidade do clima..., a mudança que a duplicação de $\mathrm{CO}_{2}$ produzirá na GATA" [anomalia da temperatura média global]; mas "a qualidade dos dados é pobre, ... e porque as mudanças são pequenas, é fácil empurrar tais dados em poucos

\footnotetext{
40 Brian Deer, "How the Case Against the MMR Vaccine was Fixed," British Medical Journal, 342, 2011: 77-82.

${ }^{41}$ Andy Coghlan, "Banned: Doctor Who Linked MMR Vaccine with Autism," The New Scientist, 18, 24 de maio de2010: 18 .

${ }^{42}$ Editores de The Lancet, "Retraction-Ileal-lymphoid-nodular Hyperplasia, Non-specific Colitis, and Pervasive Developmental Disorder in Children," The Lancet, 375, 2010: 445.

43 Paul A. Offit, “Junk Science Isn’t a Victimless Crime," Wall Street Journal, 11 de janeiro de 2011, A17.

${ }^{44}$ Porque, desde o escândalo de Watergate da era Nixon (chamado assim de acordo com o nome da construção onde se deram as travessuras), "gate" tornou-se a palavra genérica para "escândalo" - tal como no "zippergate" referindo-se ao escândalo sobre Bill Clinton e Monica Lewinsky.

${ }^{45}$ Keith Johnson, "Climate Strife Comes to Light," Wall Street Journal, 23 de novembro de 2009, A3

46 Veja Jeffrey Ball e Guy Chazan, "Report Backs Climate Data, Scolds Scientists," Wall Street Journal, 8 de julho de 2010, A13.

${ }^{47}$ Veja Patrick J. Michaels, "The Climategate Whitewash Continues," Wall Street Journal, 12 de julho de 2010 , Al5.
}

HAACK, Susan. Epistemologia: quem precisa dela? Tradução de Tiago Luís Teixeira de Oliveira. Griot : Revista de Filosofia, Amargosa - BA, v.19, n.2, p.330-342, junho, 2019. 
décimos de grau para qualquer direção"; "fica a questão de saber se o vapor de água ou as nuvens têm retorno positivo ou negativo"; etc., etc. ${ }^{48}$ Eu peguei poucas palavras de tagalog rudimentar no processo, mas logo me dei conta de que não sei o suficiente de ciência relevante para entender o argumento do Prof. Lindgren adequadamente, ou mesmo para tentar formar uma opinião própria. Isso é especialmente perturbador porque eu não sei mesmo, também, se aqueles e-mails espionados indicaram um problema comparativamente pequeno relativo a uns poucos cientistas ultrazelosos, ou se são sintomáticos de um problema sistêmico muito mais perturbador. Enquanto epistemóloga, eu não posso ajudar desejando que esta área seja - bem, com o perdão do trocadilho, menos calorosa.

Mas não podemos, por enquanto, ao menos ter certeza de que vacinas e implantes de seios são inofensivos? Podemos estar confiantes de que a suposta evidência de uma conexão entre implantes de seios de silicone e desordens do tecido conjuntivo era frágil; mas daí não se segue que implantes de seios não trazem perigos. De fato, enquanto eu escrevia este artigo a FDA lançou um alerta de que, em alguns poucos casos, implantes de seios podem estar ligados a uma forma rara de câncer. ${ }^{49}$ Podemos estar confiantes de que a suposta evidência de conexão entre a vacina $\mathrm{SRC}$, distúrbios do intestino, e autismo era fraudulenta; mas novamente, não se segue daí que vacinas não trazem perigos. Sabemos que sim: e.g., em 1976 os E.U.A. precisaram suspender um programa massivo de vacinação contra a gripe suína por causa de um aumento significativo de casos de síndrome de Guillian-Barré entre os recentemente vacinados. ${ }^{50}$

De fato, a descoberta da fraude de Wakefield não mostra sequer que não há conexão entre vacinas e autismo. $O$ número de crianças diagnosticado com autismo aumentou num período em que vacinações infantis mais abrangentes se tornaram rotina; e alguns cientistas conjecturam que o mercúrio no thimiserol (um composto usado para preservar vacinas) pode estar implicado. Em 2004, o Instituto de Medicina dos E.U.A. concluiu que tal ideia era "até o momento, ... apenas teórica"51 - não há evidência que garanta isso. Mas a controvérsia ainda fervilha; especialmente em 2007, quando, indenizando os pais de Hannah Poling com recursos provindos do fundo federal de danos por vacina, o governo dos E.U.A. reconheceu que o thimiserol contribuiu indiretamente para o autismo da criança ao exacerbar um distúrbio mitocondrial subjacente. ${ }^{52}$

Aqui também paixões correm soltas, tanto entre aqueles alarmados de que a queda na taxa de vacinação de doenças infantis caia a ponto de ameaçar novas epidemias, quanto aqueles que se alarmam pelo que parece ser um aumento significativo na taxa de autismo. Se eu tiver de adivinhar, eu diria que deve haver algum dano para umas poucas crianças com susceptibilidades especiais. (E se eu

48 Richard S. Lindgren, “The Climate Science Isn't Settled," Wall Street Journal, 1 de dezembro de 2009, A19.

49 Jennifer Corbett Dooren e Alicia Mundy, "Implants, Cancer May be Linked," Wall Street Journal, 27 de janeiro de 2011, A6.

50 David A. Freeman e Philip B. Stark, "The Swine Flu Vaccine and Guillain-Barré Syndrome: A Case Study in Relative Risk and Specific Causation," Law and Contemporary Problems, 64.4, 2001: 49-62, p. 52.

51 National Institute of Medicine, Immunization Safety Review, Washington, D.C., 2004, p. 152.

52 Thomas L. Hofmeister, "Government Agrees to Compensate Family that Claims Childhood Vaccinations Caused Autism," Developments in Mental Health Law, 27, 2008: 71-3. Três outros casos emblemáticos decididos em 2009 sustentaram que a evidência não mostrava nem que a vacina SCR, nem que o thimiserol causavam o autismo.

HAACK, Susan. Epistemologia: quem precisa dela? Tradução de Tiago Luís Teixeira de Oliveira. Griot : Revista de Filosofia, Amargosa - BA, v.19, n.2, p.330-342, junho, 2019. 
tivesse de decidir se minha criança seria vacinada eu pediria por uma dose única de vacina, sem conservadores, só por garantia). Mas tudo que eu realmente sei é que eu não sei o suficiente até mesmo para ter certeza de quanto do crescimento aparente da taxa de autismo é uma ilusão atribuível à adoção de uma definição ampla que agora inclui uma longa abrangência dos "distúrbios do espectro de autismo"; sem mencionar se, caso haja um aumento real significante, o que a evidência eventualmente deve indicar sobre sua(s) causa(s). Em resumo, novamente não sei o suficiente para ter direito a uma opinião.

E agora volto para onde comecei - com os "desconhecidos não sabidos" de Rumsfeld. Então aqui, finalmente, está minha perspectiva sobre o ponto epistemológico dele. Para avaliar quão boa era aquela evidência, e.g., Saddam Hussein tinha armas de destruição em massa, os serviços de inteligência dos EUA precisavam saber não só para onde a evidência disponível [os "conhecidos"] apontava, e quão segura ela era, mas também quão compreensiva era; e para isso, eles precisavam saber qual evidência relevante devia haver que eles não tinham [os "desconhecidos"]. Infelizmente, embora soubessem que alguma da evidência relevante era tal que era necessária, embora não a tivessem [os "desconhecidos sabidos"], eles não perceberam que outra evidência, a que eles também não tinham, era também relevante [os "desconhecidos não sabidos"]. Há uma lição aqui para todos nós. ${ }^{53}$

Autor(a) para correspondência: Tiago Luís Teixeira de Oliveira, Campo de São Cristovao, 20921-903, Rio de Janeiro - RJ, Brasil. tiagoluis@ymail.com

${ }^{53}$ Meus agradecimentos a Mark Migotti pelos úteis comentários sobre um manuscrito, e a Pamela Lucken pela ajuda na busca por materiais relevantes.

HAACK, Susan. Epistemologia: quem precisa dela? Tradução de Tiago Luís Teixeira de Oliveira. Griot : Revista de Filosofia, Amargosa - BA, v.19, n.2, p.330-342, junho, 2019. 